\title{
CONSTRUCCIONES DE LA ALTERIDAD EN LA CAUTIVA DE ESTEBAN ECHEVERRÍA
}

\section{CONSTRUCTIONS OF ALTERITY EN LA CAUTIVA FROM ESTEBAN ECHEVERRÍA}

\author{
MYRIAM MERCHÂN BARROS
}





\title{
CONSTRUCCIONES DE LA ALTERIDAD EN LA CAUTIVA DE ESTEBAN ECHEVERRÍA
}

\section{CONSTRUCTIONS OF ALTERITY EN LA CAUTIVA FROM ESTEBAN ECHEVERRÍA}

\author{
Myriam Merchán Barros
}

PALABRAS CLAVE: Alteridad, sensorium, conocimiento, identidad, paisaje social y simbólico.

KEY WORDS: Alterity, sensorium, knowledge, identity, social and symbolic landscape.

\section{RESUMEN}

Las expresiones culturales y artísticas del s. XIX son importantes para entender el desarrollo de temas y problemas que serían reescritos en las letras de los siglos XX y XXI; entre ellos, el tema de la identidad de las naciones latinoamericanas continúa pertinente. La función política de las letras del s. XIX formó y cimentó afectividades que se manifestarían en la organización y estabilización de la vida civil conociéndola y comprendiéndola para organizarla en los ámbitos sociopolíticos y culturales, desde los preceptos de la "civilización"; en la etapa de la organización de los Estados nacionales donde interactúan el liberalismo ideológico en el ámbito político y el romanticismo en el arte se escribe La cautiva, poema de Esteban Echeverría.

Proponemos reflexionar sobre las temáticas de cómo y a quién representar: el desierto, los indios y la mujer, relacionados con el dilema civilizatorio que nos invita a discernir sobre dónde sitúa la barbarie el poema La cautiva. 


\section{ABSTRACT}

Cultural and artistic expressions of the XIXth century are important for understanding the development of issues and problems that would be rewritten in the literature of the XX and XXI centuries; including the issue of identity of Latin American nations that remains relevant. The political function of literature from the XIXth century formed and established affectivities that manifest themselves in the organization and stabilization of civilian life by knowing and understanding it to be organized in socio-political and cultural fields, from the precepts of "civilization"; at the stage of the organization of national states where ideological liberalism interacts in politics and romanticism in art in which was written the poem La cautiva by Esteban Echeverria.

We propose to analyze the issues of how and who to represent: the desert, the Indians, and the women, related to the civilizing dilemma that invites us to discern where barbarism is found in the poem La cautiva.
La literatura no surge en el vacío, sino en el seno de un conjunto de discursos vivos con los que comparte muchas características. No es casualidad que a lo largo de la historia sus fronteras hayan sido cambiantes. (Todorov, 2007: 16).

La expresión "política de la literatura" implica que la literatura hace política en tanto literatura. Supone que no hay que preguntarse si los escritores deben hacer política o dedicarse en cambio a la pureza de su arte, sino que dicha pureza misma tiene que ver con la política. Supone que hay un lazo esencial entre la política como forma práctica definida del arte de escribir. (Rancière, 2011: 15)

Todo acto de conocer trae un mundo a la mano. (Maturana, 2003: 13)

\section{Narrar y poetizar la nación entre la memoria y el olvido}

Las propuestas actuales sobre el análisis de las letras en el s. XIX nos recuerdan la necesidad de considerar el paisaje social y simbólico en el cual se conformaron los Estados nacionales en América Latina; este trabajo se propone analizar las relaciones de alteridad que confrontan civilización y barbarie que se desarrollan en 
el poema La cautiva de Esteban Echeverría. Hemos elegido reflexionar sobre las temáticas de cómo y a quién representar: el desierto, los indios y la mujer, relacionados con el dilema civilizatorio que nos invita a discernir sobre dónde se sitúa la barbarie en el poema La cautiva.

En América Latina, las repúblicas -en su proceso de configuración- necesitaron ser narradas o poetizadas para identificarse como una nación: "Después de ganar la independencia, los criollos volcaron sus esperanzas hacia conquistas internas" (Sommer, 2004: 31), que les permitieran pasar a reconocerse a sí mismos y diferenciar-se de los "otros", en un ámbito cargado de un "Romanticismo heroico que [...] se caracteriza por su desconocimiento a lo aborigen, su negación a la etapa colonial y una concepción de lo nacional acorde con el surgimiento de los Estados Nacionales." (García Yépez y Rodríguez Rojas, sf.) Los escritores intervenían activamente en la vida pública y se comprometían con la acción política, necesitaban comprender y organizar la sociedad civil; la literatura configuró imaginarios en el proceso de formación del ciudadano como agente de civilización -para ciertas élites-, estableció acciones fundacionales donde la imaginación tenía como objetivo conferir forma y sentido a una subjetividad "nacional" desde el autoconocimiento que demandaba la construcción de la identidad: ....el fenómeno nacional no puede ser correctamente analizado sin tomar en cuenta y con mucho cuidado, la invención de la tradición. ... lo esencial de una nación se encuentra en el hecho que todos sus individuos comparten su patrimonio común, pero también en el hecho que todos hayan olvidado muchas otras cosas:

El olvido y yo diría que, hasta el error histórico, son un factor esencial en la creación de una nación, de modo que el progreso de los estudios históricos es a menudo un peligro para la nacionalidad. La investigación histórica, en efecto, proyecta luz sobre hechos de violencia que ocurrieron en los orígenes de todas las formaciones políticas, incluso aquellas cuyas consecuencias han sido más beneficiosas. La unidad se hace siempre de modo brutal. [Ernest Renan. ¿Qué es una nación?] (Pecchinenda, 2000: 60)

La función política de las letras del s. XIX formó y cimentó afectividades que se manifestarían en la organización y estabilización de la vida civil conociéndola y comprendiéndola para organizarla en los ámbitos sociopolíticos y culturales, desde los preceptos de la "civilización": 
...formar al ciudadano, al agente civil y civilizado de las nuevas repúblicas...Es así como el hombre de letras, además de estar creando una incipiente literatura nacional, reflexionaba y participaba activamente en la formulación de ideas y proyectos constitucionales, legislativos, educacionales, etc., como otra manera de contribuir a la construcción de las nuevas repúblicas. (Osorio, 2000: 43)

Estudiar las expresiones culturales y artísticas del s. XIX es importante para entender el desarrollo de temas y problemas que serían reescritos en las letras de los siglos XX y XXI, especialmente si consideramos que la reflexión sobre el tema de la identidad de las naciones latinoamericanas continúa siendo pertinente:

A través de la idea de la nación, que en el fondo es una innovación histórica bastante nueva, se puede comprender mejor la importancia crucial de la relación entre "memorias" y "tradiciones inventadas" en el proceso de construcción de los Estados modernos, sobre todo por lo que se refiere a los más jóvenes, como son seguramente todos los que pertenecen a la región latinoamericana. (Pecchinenda, 2000: 59)

Echeverría se involucró con el desarrollo de la idea fundamental de nación; con el proyecto de la formación de una conciencia nacional, fue el líder de la "Joven Generación", planteó un liberalismo moderno, fue un visionario y consiguió transformar el sensorium de su época desde algunas líneas de fuga: introducción del romanticismo europeo en Hispanoamérica, inauguración de la literatura nacional moderna al incorporar temas locales, aunque no haya alcanzado a asumir su realidad en toda su complejidad :"...con la incorporación del paisaje de la pampa que llama $<<$ el desierto $>>-$, el enfrentamiento entre criollos e indios y la naturaleza salvaje, la temática nacional se hace centro de la obra.[...]En Echeverría se ilustra con bastante propiedad la manera nacional específica en que el romanticismo se manifiesta en América... (Osorio 2000, 42) como lo propone Osorio-, donde interactúan el liberalismo ideológico en el ámbito político y el romanticismo en el arte, estuvo acentuada por el interés de los valores propios, pues los proyectos de integración continental se habían disuelto en guerras civiles, enfrentamientos entre caudillos, que dieron como resultado el desgobierno que señalaba el camino hacia la anarquía y que produjo como 
resultado luchas caudillistas, guerras internas, (Osorio 2000, 40) y descontento manifiesto contra el despotismo.

La cautiva, calificada como un relato en verso, aparece en un contexto socio-político complejo: en 1833, Rosas había emprendido la Campaña, su expedición al desierto para eliminar el "problema del indio"y con ello, la barbarie; se había propuesto imponer la "civilización"; el dictador afirmaba que había conseguido su objetivo, pero, aunque murieron miles de indios pampas, "el problema" persistía:

El concepto de "civilización", es de data reciente, fue utilizado por los franceses en el siglo XVIII para oponerlo al de "barbarie"; tal como lo define Huntington (1997): "la civilización es el agrupamiento cultural más elevado y el grado más amplio de identidad cultural que tienen las personas [...] son el nosotros más grande..."(García Yépez and Rodríguez Rojas, sf: 48).

Este poema es el primero de la antología Rimas, donde además de La cautiva, encontramos Himno al dolor, Al corazón y Canciones. (Echeverría, Rimas 1984) La edición cuenta con una advertencia, paratexto que devela la poética romántica de Echeverría, una clave de lectura esencialmente referida a su poema protagónico inicial además de poner bajo la consideración de la opinión pública en general el grado de su conocimiento certificado -todas las referencias que utiliza, las relaciones de transtextualidad que desarrolla para evidenciar la episteme que fundamentaba su posición frente al arte: su designio es "pintar algunos rasgos de la fisonomía poética del Desierto" -sería importante recordar que "...en el siglo XIX lo que estaba más allá de la frontera suponía una amenaza pero también encerraba un deseo de apropiación, de incorporación, era una zona civilizable" (Rodríguez 2010)-; se propuso situar en el Desierto a "dos almas ideales" unidas por el vínculo del amor infortunado; declaró que la poesía entraba en el dominio de lo posible, presentaba la energía de la pasión: "Para los primeros románticos: [...] el arte sigue siendo conocimiento del mundo. La única novedad, de haberla, es su juicio de valor sobre los diferentes modos de conocimiento. Aquel al que se accede por la vía del arte les parece superior al de la ciencia". (Todorov, 2007: 67) Echeverría critica la poesía "facticia" de ideas altisonantes y follaje pomposo, las voces "campanudas" que se usan para referirse a "nimiedades"; es contrario a los oradores "gerundios" y a las poetas sin alma, pues la función de la verdadera poesía es representar lo bello" $<<$ La finalidad del verdadero 
arte no es imitar la naturaleza, sino crear belleza >>" señalaba Winckelman (Todorov, 2007: 72)-; propone imágenes que relacionan al poeta con las prácticas -la techne- de otros campos artísticos que tiene como fin conseguir lo bello: "La belleza se define como aquello que, en el plano funcional, no tiene un fin práctico, y a la vez como aquello que, en el plano estructural, se organiza con el rigor de un cosmos." (Todorov, 2007: 50) Reivindica la originalidad en la poesía: no se limitará a adecuarse a un patrón dado, no cree en la poesía como acción mecánica que demuestra la carencia de la "facultad generatriz", ya que así solo produciría una poesía falsa, destinada exclusivamente para los sentidos; pedestre, pues adolece de sencillez prosaica, copia lo vulgar y no puede ver lo poético esencial, hace gala en verso y rima, pero se vacía de significado; esto da pie a la convicción que la poesía miente y exagera; Echeverría declara su aversión a las preceptivas neoclásicas que pretenden catalogar: no hay que seguir moldes conocidos ni imitar modelos, la poesía real ni miente, ni exagera, es lo más íntimo que produce la inteligencia, está asida al pensamiento, no necesita de calificaciones arbitrarias: "Preciso es que (la poesía) aparezca revestida de un carácter propio y original, que reflejando los colores de la naturaleza, física que nos rodea, sea a la vez un cuadro vivo de nuestras costumbres, y la expresión más elevada de nuestras ideas dominantes... sentimientos, pasiones e intereses sociales." (Jitrik 1967, 23) Declara también que el verdadero poeta idealiza, busca sustituir las imperfecciones de la realidad, tratar sobre la belleza física y moral que interrelaciona ideas, afectos y acciones: "La belleza en sí no es un concepto ni objetivo (que pueda establecerse gracias a indicios materiales) ni subjetivo, es decir, que dependa del juicio arbitrario de cada quien; es intersubjetiva y por lo tanto, pertenece a la comunidad humana." (Todorov, 2007: 70-71) No le interesa "cuadrar la forma normal", se propone buscar la realización de su pensamiento, arrebatar y mover con sus palabras; reivindica lo romántico en lo estético, en la libertad, se empeña en dejar rastro en el corazón y el entendimiento; elige los octosílabos pues lo apasionan; sostiene que la poesía se completa únicamente con el ritmo pues armoniza la inspiración que ayuda a ajustarse a los movimientos de los afectos:

El metro, o mejor, el ritmo es la música por medio de la cual la poesía cautiva los sentidos y obra con más eficacia en el alma. Ora vago, pausado, remeda el reposo o las cavilaciones de la melancolía; ya sonoro y veloz, la tormenta de los afectos; con una disonancia hiere, con una armonía hechi- 
ReVista PUCE. ISSN 1390-7719.Núm.103. 3 de MAYO de 2016 -

3 DE NOVIEMBre DE 2016. Myriam MERCHÁn BARROS PP. 519-543

za; y hace, como dice Schlegel, fluctuar el ánimo entre el recuerdo y la esperanza, pareando o alternando sus rimas. El diestro tañedor modula con él en todos los tonos del sentimiento, y se eleva al sublime concierto del entusiasmo y de la pasión. (Echeverría, El matadero. La cautiva. 1990, 120)

El poeta tiene consciencia de su poder y al mismo tiempo, de su responsabilidad; "el conocimiento del conocimiento obliga", nos recuerdan Maturana y Varela (Maturana 2003, 163), "todo hacer es conocer y todo conocer es hacer":

...predomina en La cautiva la energía de la pasión manifiesta por actos; y por otra, el interno afán de su propia actividad, que poco a poco consume, y al cabo aniquila de un golpe, como el rayo, su débil existencia.

La marcha y término de todas las pasiones intensas, se realicen o no, es idéntica. ...porque el estado verdaderamente apasionado es estado febril y anormal, en el cual no puede nuestra frágil naturaleza permanecer mucho tiempo, y que debe necesariamente hacer crisis. (Echeverría, El matadero. La cautiva. 1990, 117-118)
Es importante mantenernos atentos para no caer en la tentación de las certidumbres que limitan nuestra aprehensión -lecturabilidad- del mundo, pues nuestras certidumbres impedirían que nos percatemos de su complejidad, que no puede ser únicamente nuestro mundo construido desde los prejuicios que producen las certidumbres absolutas.

El escritor es el arqueólogo o el teólogo que hace hablar a los testigos mudos de la historia común. ...Es el de desplegar un nuevo régimen de adecuación entre el significante de las palabras y la visibilidad de las cosas, el de hacer aparecer el universo de la realidad prosaica como un inmenso tejido de signos que lleva escrita la historia de una era, de una civilización o de una sociedad. (Rancière. 2011: 32).

\section{La mujer, subalterna en un espacio "otro"}

Henríquez Ureña señala que La cautiva tiene versos con sonidos opacos, que no hay magia en las imágenes, que es simple, pero con limpieza de trato, representa el espíritu del tiempo -Zeitgeist- y considera las voces de los pueblos -Stimmen der Völker- (Ureña, 2014: 174) Nuestra lectura se ha fijado 
también en el trabajo minucioso para conformar el poema: Echeverría ha construido hipálages, metonimias, metáforas, símiles, enumeraciones con gradación, hipérboles, oxímora, utiliza el hipérbaton, las preguntas retóricas, apóstrofes líricos, diálogos transtextuales para estructurar el poema en 9"partes" o cantos y un epílogo -cada uno con un título y epígrafes que pueden conformar otra historia por sí mismos, pues nos remiten a la formación que define las elecciones estéticas que ha asumido el poeta sobre el romanticismo europeo, pero también sobre el renacimiento y sus referente clásicos -recupera a Platón en la idealización de la Belleza, en la búsqueda de lo esencial; a Aristóteles y su propuesta de mímesis que incorpora el carácter anagógico del arte-:

1. ${ }^{\text {a }}$ parte, El desierto, el epígrafe de Hugo alude al espacio natural y a la determinación de emprender un camino inicial, el motivo del viaje implica el motivo del conocimiento externo y el autoconocimiento, el encuentro e interacción en las relaciones de alteridad, las pruebas, los peligros, el desarrollo de la perseverancia y por supuesto, el regreso al punto de partida como punto de llegada que descubrimos en la madurez sensata.


te y remite al tumulto altisonante, la ira, las palabras de dolor, la transformación deshumanizadora desde el alcohol que las mujeres de la "tribu aleve" no pueden controlar en sus compañeros y que fortalece los rasgos de inhumanidad.

3. ${ }^{\text {a }}$ El puñal, con un epígrafe de Calderón, anuncia muerte a manos de crueles bárbaros, pero también la hermosura y la valentía que salva, María nos recordará la dignidad de Lucrecia frente al último rey etrusco, incluso la posibilidad del suicidio si el destino se vuelve contrario y no le permite salvarse junto a su esposo.

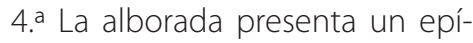
grafe de Manzoni que relaciona los muertos y la sangre que cubre la planicie, los protagonistas de la matanza son ahora los cristianos, cuyos "fieros cuchillos/ degüellan, degüellan, sin sentir horror", una venganza inexorable que se transforma en perfidia, en miasma para la naturaleza que tiñe la hierba con sangre hedionda y recuerda la hybris de los criollos.

5. a El pajonal, nuevamente el epígrafe corresponde a Dante quien nos recuerda que el ánimo cansado nutre y conforta: María salva a Brian, el dolor está presente, se focaliza en los héroes, pero cuentan con el piadoso cielo como aliado que alivia sus tormentos.


Moreto, anuncia la extensión de las horas del deseo, la fuerza del amor que es fe inspirada, religión, esperanza, fuente inagotable que confía en el nuevo día y en su salvación. 
7. ' La quemazón, con un epígrafe de Lamartine invita a contemplar cómo se extiende la llama que reduce los "pastales", los cardos, los pajonales y animales a ceniza como si el día del juicio final hubiese llegado.

8. Brian, con un epígrafe de Antar alude a la victoria y la fama que se han logrado gracias a la espada, representa el héroe paradigmático, que aunque debilitado en su confrontación con los indios, añora el kalós thánatos, la bella muerte que le permitiría morir defendiendo a su patria, envuelto en su bandera, haciendo sagrada su muerte.

9. María, con dos epígrafes, uno anónimo que enfatiza la extinción de la esperanza y el crecimiento del tormento, y el segundo de Petrarca que refiere la belleza de la muerte en un rostro bello, estos nos remiten también al motivo del kalós thánatos para María, ideal propio de los héroes que han conseguido cumplir su areté guerrera, ... y ella lo merece, es la recompensa a su perseverante esfuerzo y renuncia para salvar la vida de su esposo, para asumir la acción y el espacio público como su espacio natural, siempre y cuando tuviese una razón para vivir, alguien a quien amar.

El epílogo tiene un epígrafe en el que Lamartine interrelaciona la luz y el alma de quienes murieron, la voz poética asegura la trascendencia de la pareja criolla, incorpora un mito etiológico: en el lugar de la muerte de María crece un ombú cuya sombra espanta a los indios, refresca a los caminantes, constituye el lugar de encuentro de dos luces que eternizan el amor de los esposos, que nos recuerdan su trascendencia por medio de la poesía y en apariencia, la cruz que está en su base, se constituye en un signo apotropaico frente a los "bárbaros infieles". Finalmente encontramos las notas que contienen la explicación de las palabras "autóctonas", siete, que se han utilizado en el poema, y que la voz poética considera que necesita explicar, porque las conoce.

Echeverría elige a Byron para el epígrafe inicial que contextualiza y engloba el poema, califica el corazón de la mujer como suelo genial, fértil para generar los sentimientos más amables, siempre dispuesta -como la Samaritana- a ofrecer vino y aceite; nos encontramos frente a la afirmación de un poeta romántico que rompió esquemas, no únicamente formales en su propuesta poética. Curiosamente, la Samaritana nos remite al Nuevo Testamento, la mujer a quien Cristo pide agua y a quien Él se le revela como agua de vida. El vino y el aceite nos remiten al amor, a la comunión y a la unción, a la interacción entre lo espiritual y la alegría propia de la sensatez, pero también se abre la posibilidad de considerarlos como dones otorgados a los seres humanos: Dionisos, la 
euforia y el consuelo del vino y Atenea, el olivo que recuerda la perseverante y paciente sensatez reflexiva. El poema menciona varias cautivas, pero nomina únicamente a María, que se libera del cautiverio de los indios gracias a su decisión, su esfuerzo y su voluntad; pero no del cautiverio de su amor, que señala sus responsabilidades, le permite descubrir su fortaleza, y por supuesto, su incapacidad de vivir sin él. En el epílogo de Elvira o la novia del Plata, Echeverría ha citado a Wordsworth: This said that some have died for love. (Jitrik, 1967) Pero, ¿María es acaso asumida como una subalterna en el sentido que propone Gramsci?: "[un grupo no simplemente oprimido] sino carente de autonomía, sujeto a la influencia o hegemonía de otro grupo social, que no posee su propia posición hegemónica." (Bhabba, 2002: 81) Loayza advierte que ni los hombres ni las mujeres de La cautiva subvierten el orden, pues sostiene que la intencionalidad de Echeverría era "representar un tipo de mujer distinta a los modelos clásicos y socialmente aceptados; redefiniendo al sujeto femenino en función a los requerimientos que precisa la nueva nación argentina en su proceso de imaginación, delimitación y construcción. (Loayza, 2006: 924). Menciona -utilizando el concepto propuesto por Carole Patemanque, para las mujeres el contrato sexual es la base del contrato social: "Es recién por el contrato sexual en el que se definirían las relaciones de hombres y mujeres, de nuevo, a través de sus cuerpos, pero en una relación de subordinación de los primeros sobre las segundas." (Loayza 2006, 931) Sommer refiere el sensorium del siglo XIX sobre las mujeres:

Alberdi hizo más que inventar lemas; los explicó y los comentó hasta la saciedad en programas prácticos destinados a incrementar hasta la saciedad la población, no solo por medio de una política de inmigración por la que pasaría a la posteridad, sino mediante matrimonios entre los industriosos anglosajones y el "ejército" de hermosas mujeres argentinas, eminentemente equipado para la campaña eugenésica de "mejorar" la estirpe local e "ineficiente" de los españoles. ... Esto contribuyó a resolver la problemática legitimidad del hombre blanco en el Nuevo Mundo, ahora que los ilegítimos conquistadores habían sido expulsados, Sin una genealogía apropiada para arraigarlos en la Tierra, los criollos se veían obligados a sentar los derechos conyugales y después paternos, estableciendo así una pertenencia más generativa que genealógica. Debían ganarse el 
corazón y el cuerpo de América para fundarla y reproducirse como hombres cultivados. Para ser legítimo, su amor debía ser correspondido; si los padres daban el primer paso, las madres debían recibirlo de manera favorable. (Sommer, 2004: 32).

En la cautiva encontramos a María, la única mujer que es nominada y ¿tal vez por ello?- con derecho a hacer escuchar su voz, es un personaje femenino dispuesto al crimen para defender su honor; al suicidio desde la dignidad que caracteriza sus acciones y decisiones, al sacrificio -hacer sagrada- su vida por su esposo, su hijo, su patria, pero no está dispuesta a sufrir la indignidad, ni la falta de sentido en su vida, ni la aceptación pasiva de la inexorable confrontación entre las dos etnias que no se reconocen como "otros legítimos". Conservando las distancias pertinentes, hacemos referencia a las valerosas elecciones de Antígona, a la solemne dignidad de Ifigenia, posiblemente a la perspicacia y recursos de Medea que le permitían medir las situaciones adversas y encontrar metis a inteligencia recursiva- para resolverlas. Pero, cómo leemos las palabras de María, si perdemos las alusiones a las mujeres trágicas helenas: posiblemente no alcanzaríamos a leer las elecciones, las reflexiones, los temores, las acciones y las palabras de Ma- ría en toda su magnitud -incluso la que supera la concepción de su autor-creador-; podríamos recurrir a Showalter, quien nos remite a este cuestionamiento de Shosana Feldman: ¿es suficiente ser una mujer para hablar como mujer? ¿"Hablar como una mujer" está determinado por alguna condición biológica o por alguna posición estratégica o teórica, por la anatomía o por la cultura? (Culler, 1999: 48). La voz poética recuerda el dolor de María, su heroísmo, su fortaleza"varonil" a pesar de su juventud y su belleza, insiste en su soledad: "Y no hubo humana criatura/ que te ayudase a sentir", pero la poesía lo hará, consagrará su dolorosa muerte, la protegerá del olvido, se asegurará de mencionar la trascendencia de su alma, la virgen poesía le asegurará el kléos de Cypariso, le tejerá una corona de ciprés y conseguirá que admiren y veneren su nombre; la poesía puede asegurar su memoria y trascender el olvido, María ha realizado ya una katábasis al inframundo -el desierto- donde ha debido eliminar a quienes atentaban contra su dignidad. Habría que recordar que el viaje al inframundo es la máxima prueba a la que puede enfrentarse un héroe -en el Asno de oro de Apuleyo encontramos la katábasis de Psyque y la superación de las pruebas que harían posible su reencuentro con Eros-, también podríamos no perder la alusión a Alcestes, quien decidió morir voluntariamente por su esposo Ad- 
meto, dio su vida para que las moiras no tomaran aún la de él, pero fue restituida al mundo de los vivos por Heracles que descendió al Hades y rescató a Alcestes que representa la fortaleza, la entereza-.

Nosotros asumimos que es importante no conocer única y exclusivamente las dimensiones de subalteridad de María en una sociedad en la que "la mujer, que nos introduce en la situación humana y que al principio nos parece responsable de todas esas desventajas de esa situación, carga por todos nosotros con un deber pre racional de responsabilidad culpable ya para siempre después (sic)." (Dorothy Dinnerstein. The Mermaid and the Minotaur: 234.) (Culler, 1999: 529). Hemos intentado desarrollar una lectura de mujer incluyendo las alusiones clásicas, para conseguir un sistema textual más amplio, que no esté limitado por la visión que producen los conceptos que ha producido la autoridad del hombre:

Para una mujer leer como una mujer no es repetir una identidad o una experiencia ya dada sino representar un papel que construye con referencia a su identidad como mujer, que también ha sido construida de manera que la serie puede continuar: una mujer leyendo como una mujer leyendo como una mujer. La no coinciden- cia revela un intervalo, una división dentro de la mujer o de cualquier sujeto lector y la experiencia de ese sujeto. (Culler, 1999: 61)

La literatura es indisolublemente una ciencia de la sociedad y la creación de una mitología nueva. A partir de eso se define la identidad de una poética y de una política. El nuevo régimen de significación que destituye de sus privilegios a la voluntad de significar y la palabra en acto define también una distancia por relación a la escena político democrática. (Rancière, 2011: 39)

\section{El Desierto, un espacio de encuentro con la subalteridad del otro}

El desierto juega un papel protagónico en la parte primera del poema, 180 versos. El epígrafe elegido es de Víctor Hugo, de su poema Mazzepa (Echeverría, Rimas 1984, 85), contiene una referencia a la acción, a la determinación de ir y adentrarse en un gran espacio ignoto, tan grande, que se convierte en un reto, o se lo conquista o se sucumbe en él:

Alberdi y Sarmiento coincidieron, esta vez, en la necesidad de poblar el desierto, de hacerlo desa- 